\title{
HUBUNGAN KARAKTERISTIK INOVASI DENGAN TINGKAT ADOPSI PETANI TERHADAP KOMPONEN PENGENDALIAN HAMA TERPADU (PHT) PADI SAWAH DI KELURAHAN LIABUKU KECAMATAN BUNGI KOTA BAUBAU
}

\author{
Wa Ode Dian Purnamasari \\ Program Studi Agribisnis Fakultas Peranian \\ Universitas Muhammadiyah Buton \\ Jln. Betoambari No. 36 Baubau \\ e-mail: waodedianpurnamasari@gmail.com
}

\begin{abstract}
This research was conducted from November to December 2018 in Liabuku Village, Bungi Subdistrict, Baubau Town, with the aim of knowing the characteristics of innovation consisting of relative advantages, compatibility, complexity, trialability, and observability and types of innovation decisions in SLPHT rice plants; know the level of adoption of SLPHT farmers for integrated pest control components; know the relationship between the characteristics of innovation consisting of relative advantages, compatibility, complexity, trialability and observability, as well as the type of innovation decisions with the level of SLPHT farmers' adoption of the Integrated Pest Management (IPM) component. The number of respondents was 30 who had attended SLPHT. The data analysis technique used is the analysis of the average and standard deviations and Spearman rank correlation test. To find out the difference in the level of adoption of the IPM components of rice between SLPHT and Non-SLPHT farmers using t-test. Based on the results of research and discussion, it is found that the characteristics of innovation of farmers provide a relative advantage for farmers, $60 \%$ of farmers say there is compatibility of trialability with pest control needs, and $40 \%$ of respondents state that innovation is sometimes not according to needs. The adoption rate of SLPHT farmers to the IPM component was 40\% of farmers using varieties of lowland rice according to recommendations, $60 \%$ using superior rice not in accordance with recommendations. For fertilization, $20 \%$ of farmers fertilize according to recommendations, and $80 \%$ of farmers fertilize not according to recommendations. For integrated pest control, $50 \%$ of farmers conduct IPM, the remaining $50 \%$ carry out pest control with certain techniques. For the use of natural enemies, $83.33 \%$ of farmers did not utilize natural enemies, the rest, $16.67 \%$ did not use natural enemies. For routine observations, $90 \%$ of farmers do routine observations but not every week, only $10 \%$ of farmers do every week. And observations made are only part of the observation stages. For the wise use of pesticides, all farmers combine pesticides with other techniques. There is a significant relationship between the characteristics of compatibility innovation with the use of natural enemies as indicated by the sig correlation value is 0.05 smaller. There is a significant relationship between complexity with routine observations which is shown by the correlation sig value is 0.013 smaller 0.05 .
\end{abstract}

Keywords: Relationship, characteristics, innovation, adoption, IPM, farmers, lowland rice 


\begin{abstract}
Abstrak
Penelitian ini dilaksanakan pada Bulan November sampai dengan bulan desember 2018 di Kelurahan Liabuku Kecamatan Bungi Kota Baubau, dengan tujuan mengetahui karakteristik inovasi yang terdiri dari keuntungan relatif, kompatibilitas, kompleksitas, triabilitas, dan observabiltas serta tipe keputusan inovasi dalam SLPHT tanaman padi; mengetahui tingkat adopsi petani SLPHT terhadap komponen pengendalian hama terpadu; mengetahui hubungan antara karakteristik inovasi yang terdiri dari keuntungan relatif, kompatibilitas, kompleksitas, triabilitas dan observabilitas, serta tipe keputusan inovasi dengan tingkat adopsi petani SLPHT terhadap komponen Pengendalian Hama Terpadu (PHT). Jumlah responden sebanyak 30 yang pernah mengikuti SLPHT. Teknik analisis data digunakan adalah analisis rata-rata dan standar deviasi dan uji korelasi jenjang spearman (rank spearman.) Untuk mengetahui perbedaan tingkat adopsi terhadap komponen PHT tanaman padi antara petani SLPHT dan Non SLPHT menggunakan uji t ( $t$ - test). Berdasarkan hasil penelitian dan pembahasan diperoleh bahwa karakteristik inovasi petani memberikan keuntungan relatif bagi petani, $60 \%$ petani menyatakan ada kesesuaian inovasi dengan kebutuhan pengendalian hama, dan $40 \%$ responden menyatakan inovasi kadang tidak sesuai dengan kebutuhan. Tingkat adopsi petani SLPHT terhadap komponen PHT sebanyak $40 \%$ petani menggunakan varietas padi sawah sesuai rekomendasi, $60 \%$ menggunakan padi unggul tidak sesuai rekomendasi. Untuk pemupukan, $20 \%$ petani melakukan pemupukan sesuai rekomendasi, dan $80 \%$ petani melakukan pemupukan tidak sesuai rekomendasi. Untuk pengendalian hama terpadu, 50\% petani melakukan PHT, sisanya, yaitu 50\% melakukan pengendalian hama dengan teknik tertentu. Untuk pemanfaatan musuh alami, 83,33\% petani kurang memanfaatkan musuh alami, sisanya, $16,67 \%$ tidak memanfaatkan musuh alami. Untuk pengamatan rutin, 90\% petani melakukan pengamatan rutin tapi tidak tiap minggu, hanya $10 \%$ petani yang melakukan tiap minggu. Dan pengamatan yang dilakukan hanya sebagian tahapan pengamatan. Untuk penggunaan pestisida secara bijak, semua petani mengkombinasikan pestisida dengan teknik lain. Ada hubungan yang signifikan antara karakteristik inovasi kompatibilitas dengan pemanfaatan musuh alami yang ditunjukan dengan nilai sig korelasi adalah 0,05 lebih kecil. Ada hubungan yang signifikan antara kompleksitas dengan pengamatan rutin yang ditunjukan dengan nilai sig korelasi adalah 0,013 lebih kecil 0,05.
\end{abstract}

Kata Kunci: Hubungan, karakteristik, inovasi, adopsi, PHT, petani, padi sawah

\title{
PENDAHULUAN
}

Sejak zaman dahulu peranan komoditi pangan di Indonesia, khususnya padi begitu besar, sebab padi merupakan bahan makanan pokok bagi sebagian besar penduduk Indonesia. Kebutuhan bahan pangan berupa padi tidak pernah surut, melainkan kian bertambah dari tahun ke tahun sesuai dengan pertumbuhan penduduk. Untuk mengimbangi dan mengatasi kebutuhan pangan yang semakin meningkat, petani diharapkan dapat bekerja keras guna meningkatkan dan melipat-gandakan produksi bahan pangan padi.

Faktor faktor pengendalian hama penyakit dalam budidaya tanaman padi memegang peranan penting. Bagaimanapun suburnya tanah, cocoknya iklim, unggulnya bibit atau ketepatan pemupukan tanaman tidak akan memberikan hasil panen yang memuaskan bila terserang hama dan penyakit. Kadang akibatnya tidak hanya kegagalan panen, tetapi juga matinya tanaman sehingga kerugiannya sangat besar. Apalagi investasi di bidang pertanian 
saat ini dilakukan secara besar-besaran. Tak pelak lagi pemahaman dan penguasaan tentang hama dan penyakit mutlak diperlukan (Pracaya, 2004).

Salah satu cara untuk mengatasi kendala serangan hama dan penyakit tanaman yang sering digunakan oleh petani adalah dengan penggunaan pestisida, namun penggunaan pestisida secara terus menerus dan berlebihan akan menimbulkan dampak yang kurang baik bagi tanaman dan lingkungan, seperti munculnya hama resisten, hama-hama sekunder, dan masalah pencemaran lingkungan. Maka dari itu diperlukan adanya suatu teknik pengendalian yang tetap memperhatikan aspek lingkungan yang dikenal dengan Pengendalian Hama Terpadu (PHT).

Pengendalian Hama Terpadu (PHT) adalah teknologi pengendalian hama dengan pendekatan komperhensif berdasarkan ekologi yang dalam keadaan lingkungan tertentu mengusahakan pengintegrasian berbagai taktik tertentu yang kompetibel satu sama lain, sehingga populasi hama dapat dipertahankan dibawah jumlah-jumlah yang secara ekonomis tidak merugikan, mempertahankan kelestarian lingkungan dan menguntungkan bagi petani (Oka, 1995).

Sehubungan dengan hal tersebut diatas perlu dilakukan pembinaan pengendalian OPT pada tanaman padi dengan Metode PHT melalui kegiatan Sekolah Lapang Pengendalian Hama Terpadu (SLPHT), dimana petani dilatih untuk mengelola tanaman atau OPT dengan memadukan beberapa teknik pengendalian yang harmonis dan kompatibel.

Melalui kegiatan SLPHT, para petani sebagai anggota kelompok tani dididik untuk meningkatkan pengetahuan secara bertahap tentang siklus hidup hama dan sifat serangannya yang berkaitan erat dengan usia tanaman serta meningkatkan ketrampilan dalam berusaha tani. Hal ini akan memberikan manfaat yang besar bagi petani untuk melakukan dugaan kemungkinan serangan berikutnya.

Hama dan penyakit tanaman merupakan salah salah faktor yang mempengaruhi produksi padi sawah, jika intensitas serangan hama dan penyakit populasinya tinggi maka akan menyebabkan produksi padi sawah rendah. Berikut data luas tanam, luas panen, produksi dan produktifitas padi sawah di kota Baubau tahun 2015- 2017.

Tabel 1. Luas Tanam, Luas Panen, Produksi dan produktifitas Padi Sawah di Kota Baubau Tahun 2015-2017

\begin{tabular}{|c|c|c|c|c|c|c|c|}
\hline No. & Tahun & $\begin{array}{l}\text { Luas } \\
\text { (Ha) }\end{array}$ & Tanam & $\begin{array}{l}\text { Luas } \\
\text { (Ha) }\end{array}$ & Panen & $\begin{array}{l}\text { Produksi } \\
\text { (ton) }\end{array}$ & $\begin{array}{l}\text { Produktifitas } \\
\text { (ton/Ha) }\end{array}$ \\
\hline 1 & 2015 & 2016 & & 2016 & & $11.289,6$ & 5,6 \\
\hline 2 & 2016 & 2141 & & 2141 & & 10.020 & 4,63 \\
\hline 3 & 2017 & 1988 & & 1912 & & $8.202,9$ & 4,29 \\
\hline
\end{tabular}

Sumber:Dinas Pertanian Kota Baubau, tahun 2017

Berdasarkan Tabel 1 diatas menunjukan bahwa produksi dan produktifitas padi sawah dalam kurun waktu tiga tahun terakhir mengalami penurunan yaitu pada tahun 2015 produksi padi sawah sebesar $11.289,6$ ton dengan produktifitas yang dicapai sebesar 5,6 ton/ha mengalami penurunan produksi dan produktifitas pada tahun 2016 yaitu produksi menjadi 10.020 ton dengan tingkat produktifitas sebesar 4,63 ton/Ha demikian halnya pada tahun 2017 terjadi penurunan produksi menjadi 8.202,9 ton dan produktifitas menjadi 4,29 ton/Ha. Hal ini disebabkan karena berkurangnya luas panen. Luas panen yang berkurang ini salah satunya disebabkan oleh adanya serangan hama dan penyakit yang tinggi. Oleh karena itu perlu memberikan pemahaman kepada petani agar bisa mengadopsi teknologi PHT untuk mengurangi serangan hama dan penyakit yang menyerang tanaman padi sawah. 
Faktor-faktor yang mempengaruhi petani dalam mengadopsi teknologi PHT seperti pendidikan (Mardiakanto, 1993 dan Mosher,1968), kekosmopolitan (Rogers dan Shoemaker ,1986), motivasi petani (Wijayanto, 2005), kehadiran petani dalam penyuluhan dan self efficacy (Bandura dalam Hariadi ,2004) peran penyuluh (Mardikanto,1993), peran ketua kelompok (Soekanto, 1987). Apakah faktor-faktor tersebut ini juga berpengaruh terhadap adopsi petani dalam mengelola tanaman terpadu padi sawah.

Berdasarkan latar belakang diatas maka yang menjadi masalah dalam penelitian ini adalah: (1) Bagaimana karakteristik inovasi yang terdiri dari keuntungan relatif, kompatibilitas, kompleksitas, triabilitas, dan observabiltas dapat mempengaruhi tingkat adopsi petani dalam SLPHT tanaman padi sawah di Kelurahan Liabuku Kecamatan Bungi Kota Baubau? (2) Bagaimana tingkat adopsi petani SLPHT terhadap komponen Pengendalian Hama Terpadu (PHT) tanaman padi sawah di Kelurahan Liabuku Kecamatan Bungi Kota Baubau? (3) Bagaimana hubungan antara karakteristik inovasi yang terdiri dari keuntungan relatif, kompatibilitas, kompleksitas, triabilitas, dan observabiltas dengan tingkat adopsi petani SLPHT terhadap komponen Pengendalian Hama Terpadu (PHT) tanaman padi sawah di Kelurahan Liabuku Kecamatan Bungi Kota Baubau?

Tujuan yang dicapai dalam penelitian ini adalah (1) untuk mengetahui karakteristik inovasi yang terdiri dari keuntungan relatif, kompatibilitas, kompleksitas, triabilitas, dan observabiltas serta tipe keputusan inovasi dalam SLPHT tanaman padi di Kelurahan Liabuku Kecamatan Bungi Kota Baubau, (2) Mengetahui tingkat adopsi petani SLPHT terhadap komponen pengendalian hama terpadu di Kelurahan Liabuku Kecamatan Bungi Kota Baubau (3) Mengetahui hubungan antara karakteristik inovasi yang terdiri dari keuntungan relatif, kompatibilitas, kompleksitas, triabilitas dan observabilitas, serta tipe keputusan inovasi dengan tingkat adopsi petani

SLPHT terhadap komponen Pengendalian Hama Terpadu (PHT) di Kelurahan Liabuku Kecamatan Bungi Kota Baubau.

Manfaat yang diharapkan dari penelitian ini adalah:

1. Bagi pemerintah dan instansi terkait, yaitu kantor dinas pertanian, sebagai bahan pertimbangan pembuat kebijakan pemerintah untuk memajukan kehidupan masyarakat di Indonesia, khususnya petani padi di daerah diadakan penelitian.

2. Bagi peneliti lain dapat digunakan sebagai bahan pembanding dan referansi untuk melakukan penelitian sejenis.

\section{METODE PENELITIAN}

Lokasi dan waktu penelitian ini dilaksanakan pada bulan November sampai dengan Desember 2018 di Kelurahan Liabuku Kecamatan Bungi Kota Baubau dengan pertimbangan bahwa di Desa tersebut pernah diadakan SLPHT tanaman padi sawah.

Metode yang digunakan dalam penelitian ini adalah metode penelitian survei yaitu penelitian yang mengambil sampel dari satu populasi dan menggunakan kuisioner sebagai alat pengumpul data yang pokok (Singarimbun dan Effendi, 1989). Populasi dalam penelitian ini adalah peserta SLPHT tanaman padi yang ada di Kelurahan Liabuku Kecamatan Bungi Kota Baubau. Responden dalam penelitian ini diambil dengan menggunakan cara sensus yaitu semua unit populasi diambil sebagai sumber data atau informan (Mardikanto, 2001). Jumlah responden yang diambil sebanyak 30 yang pernah mengikuti SLPHT.

Jenis dan sumber data menggunakan data primer dan data sekunder. Data primer dalam 
penelitian ini diperoleh langsung dari petani responden melalui wawancara langsung dengan menggunakan kuesioner yang telah disiapkan. Data sekunder diperoleh dari Dinas Pertanian Kota Baubau.

Teknik pengumpulan data dengan wawancara, observasi dan pencatatan. Teknik wawancara digunakan untuk mengumpulkan data primer melalui wawancara langsung kepada responden berdasarkan daftar pertanyaan (kuesioner) yang telah disiapkan sebelumnya. Teknik observasi dilakukan dengan mengadakan pengamatan langsung terhadap objek yang akan diteliti sehingga didapatkan gambaran yang jelas mengenai objek yang akan diteliti. Sedangkan teknik pencatatan digunakan untuk mengumpulkan data sekunder yaitu dengan mencatat data yang ada pada instansi pemerintah yang terkait dengan penelitian ini.

Variabel yang diamati pada penelitian ini yaitu:

1. Identitas responden: umur, pendidikan, luas lahan dan jumlah tanggungan keluarga.

2. Karateristik inovasi: keuntungan relatif, kompatibilitas, kompleksitas, triabilitas, dan observabilitas.

3. Tingkat Adopsi Komponen PHT: budidaya tanaman sehat, pengamatan rutin, pemanfaatan musuh alami, dan penggunaan pestisida secara bijaksana.

Data yang telah dikumpulkan di lapangan diolah dengan mentabulasikan dan seterusnya dipindahkan kedalam bentuk tabularis sesuai dengan kebutuhan analisis.

1. Untuk mengetahui kecenderungan rata-rata antara faktor yang mempengaruhi tingkat adopsi yang meliputi keuntungan relatif, kompatibilitas, kompleksitas, triabilitas, observabilitas dan tingkat adopsi petani SLPHT digunakan analisis rata-rata dan standar deviasi

2. Untuk mengetahui tingkat signifikansi hubungan antara faktor yang mempengaruhi tingkat adopsi yang meliputi keuntungan relatif, kompatibilitas, kompleksitas, triabilitas, dan observabilitas dengan tingkat adopsi petani dalam kegiatan SLPHT digunakan uji korelasi jenjang spearman (rank spearman) dengan menggunakan rumus sebagai berikut:

$$
r s=1-\frac{6 \sum_{i=1}^{N} d i^{2}}{N^{3}-N}
$$

dimana: rs = koefisien korelasi rank spearman

$\mathrm{di}=$ beda rangking

$\mathrm{N}=$ jumlah sampel

Untuk $\mathrm{N} \geq 10$ digunakan rumus:

$$
t=r s \sqrt{\frac{N-2}{1-r s^{2}}}
$$

Kriteria pengambilan keputusan:

- jika t hitung > t table, maka Ho diterima berarti ada hubungan yang signifikan antara faktor-faktor yang mempengaruhi tingkat adopsi dengan tingkat adopsi petani dalam kegiatan SLPHT.

- jika $\mathrm{t}$ hitung $\leq \mathrm{t}$ table, maka Ho ditolak berarti ada hubungan yang tidak signifikan antara faktor-faktor yang mempengaruhi tingkat adopsi dengan tingkat adopsi petani dalam kegiatan SLPHT

3. Untuk mengetahui perbedaan tingkat adopsi terhadap komponen PHT tanaman padi 
antara petani SLPHT dan Non SLPHT menggunakan uji t (t-test). Tes ini digunakan untuk signifikansi perbedaan, dengan rumus sebagai berikut:

$$
t=\frac{\left|X_{1}-X_{2}\right|}{\sqrt{\frac{\left.\left(n_{1}-1\right) S d_{1}^{2}+\left(n_{2}-1\right) S d_{2}^{2}\right)\left(1 / n_{1}+1 / n_{2}\right)}{\left(n_{1}+n_{2}\right)-2}}}
$$

Keterangan:

$\mathrm{X}_{1} \quad$ : rata-rata tingkat adopsi petani peserta SLPHT

$\mathrm{X}_{2}$ : rata-rata tingkat adopsi petani non SLPHT

$\mathrm{Sd}_{1}^{2}$ : varian pengetahuan petani peserta SLPHT

$\mathrm{Sd}_{2}{ }^{2}$ : varian pengetahuan petani non SLPHT

$\mathrm{n}_{1} \quad$ : jumlah petani SLPHT

$\mathrm{n}_{2} \quad$ : jumlah petani non SLPHT

Kriteria pengambilan keputusan:

1. Jika $\mathrm{t}$ hitung $\geq \mathrm{t}$ tabel maka Ho ditolak, berarti terdapat perbedaan yang signifikan antara tingkat adopsi petani peserta SLPHT dengan non SLPHT.

2. Jika $t$ hitung $<\mathrm{t}$ tabel maka Ho diterima, berarti tidak terdapat perbedaan yang signifikan antara tingkat adopsi petani peserta SLPHT dengan petani non SLPHT.

\section{PEMBAHASAN}

\section{Hubungan Karakteristik Inovasi dengan Tingkat Adopsi Komponen Pengendalian Hama Terpadu (PHT)}

Berdasarkan hasil analisis menggunakan aplikasi SPSS versi 2.0, diperoleh nilai ratarata dan standar deviasi data kuesioner responden sebagai berikut:

Tabel 2. Nilai Rata-Rata dan Standar Deviasi Data Kuesioner Responden petani Padi Sawah di Kelurahan Liabuku Kecamatan Bungi Kota Baubau

\begin{tabular}{lll}
\hline Kelompok Data & Rata-rata & Standar Deviasi \\
\hline Karakteristik Inovasi & & \\
\hline$-\quad$ Keuntungan pelaksanaan inovasi & 1,0000 & 0 \\
\hline$-\quad$ Kompatibilitas & 1,4000 & 0,49827 \\
\hline$-\quad$ Kompleksitas & 1,1667 & 0,37905 \\
\hline$-\quad$ Triabilitas & 1,0000 & 0 \\
\hline$\quad$ Observabilitas & 1,0000 & 0 \\
\hline Tingkat Adopsi Komponen PHT & 1,7048 & 0,17570 \\
\hline$\quad$ Budidaya Tan. Sehat & 1,8500 & 0,32563 \\
\hline$-\quad$ Pemanfaatan Musuh Alami & 1,9500 & 0,15256 \\
\hline$-\quad$ Pengamatan Rutin & 2,0000 & 0 \\
\hline
\end{tabular}

Tabel 2 diatas menunjukan bahwa nilai standar deviasi sebesar 0 , artinya tidak ada variasi jawaban yang diberikan responden, semua responden memberikan jawaban yang 
sama, yaitu untuk keuntungan pelaksanaan inovasi, triabilitas, observabilitas dan penggunaan pestisida secara bijak. Semua responden menyatakan bahwa inovasi memberikan keuntungan finansial (nilai pilihan 1 pada keuntungan pelaksanaan inovasi adalah ada keuntungan usahatani padi sawah). Semua responden menyatakan bahwa inovasi tersebut mudah dicoba terlebih dahulu dalam ukuran/skala kecil (nilai pilihan 1 pada triabilitas). Karakteristik inovasi lain yang semua responden menjawab sama adalah observabilitas, dimana semua responden menjawab 1 yang artinya inovasi tersebut mudah diamati proses dan hasilnya. Selanjutnya untuk tingkat adopsi komponen PHT yang standar deviasinya sebesar 0 adalah penggunaan pestisida secara bijak, yaitu dalam penggunaan pestisida, semua responden mengkombinasikan penggunaan pestisida dengan teknik pengendalian hama lainnya. Untuk melihat karakteristik inovasi penerapan teknologi pengendalian hama terpadu lebih lanjut dapat dilihat pada Tabel 12 berikut:

Tabel 3. Rekapitulasi Jawaban Responden pada Karakteristik Inovasi Penerapan Teknologi Pengendalian Hama Terpadu

\begin{tabular}{|c|c|c|c|}
\hline Karakteristik Inovasi & Pilihan & $\begin{array}{l}\text { Jumlah Pemilih } \\
\text { (jiwa) }\end{array}$ & $\begin{array}{l}\text { Persen } \\
(\%) \\
\end{array}$ \\
\hline \multirow[t]{3}{*}{ Keuntungan Relatif } & $\mathrm{Ya}$ & 30 & 100 \\
\hline & kadang-kadang & 0 & 0 \\
\hline & Tidak & 0 & 0 \\
\hline \multirow{3}{*}{ Kompatibilitas } & Sesuai & 18 & 60 \\
\hline & Kadang sesuai & 12 & 40 \\
\hline & Tidak sesuai & 0 & 0 \\
\hline \multirow[t]{3}{*}{ Kompleksitas } & Mudah & 25 & 83,33 \\
\hline & Sedang & 5 & 16,67 \\
\hline & Sulit & 0 & 0 \\
\hline \multirow[t]{3}{*}{ Triabilitas } & Mudah & 30 & 100 \\
\hline & Sedang & 0 & 0 \\
\hline & Sulit & 0 & 0 \\
\hline \multirow[t]{3}{*}{ Observabilitas } & Mudah & 30 & 100 \\
\hline & Sedang & 0 & 0 \\
\hline & Sulit & 0 & 0 \\
\hline
\end{tabular}

Tabel 3 menunjukkan bahwa 100\% responden menyatakan bahwa inovasi memberikan keuntungan relatif bagi petani di Kelurahan Liabuku. Sebanyak $60 \%$ responden menyatakan ada kesesuaian inovasi dengan kebutuhan pengendalian hama padi sawah, dan sebanyak $40 \%$ responden menyatakan inovasi kadang sesuai dengan kebutuhan. Untuk kompleksitas, $83,33 \%$ responden menyatakan inovasi tersebut mudah dimengerti dan dilaksanakan, hanya $16,67 \%$ responden yang menyatakan inovasi tersebut sedang (cukup) untuk dimengerti dan dilaksanakan. Untuk triabilitas, semua responden (100\% responden) menyatakan bahwa inovasi tersebut mudah dicoba terlebih dahulu dalam ukuran/skala kecil, dan untuk observabilitas, semua responden (100\% reponden) menyatakan bahwa inovasi tersebut mudah 
diamati proses dan hasilnya. Untuk melihat besarnya tingkat adopsi komponen PHT pada petani Kelurahan Liabuku dapat dilihat pada Tabel 4 berikut:

Tabel 4. Rekapitulasi Jawaban Responden pada Tingkat Adopsi Komponen PHT

\begin{tabular}{|c|c|c|c|}
\hline Tingkat Adopsi & Pilihan & $\begin{array}{l}\text { Jumlah } \\
\text { Pemilih } \\
\text { (jiwa) }\end{array}$ & $\begin{array}{l}\text { Persen } \\
(\%)\end{array}$ \\
\hline \multicolumn{4}{|l|}{ Budidaya Tanaman Sehat } \\
\hline \multirow{3}{*}{$\begin{array}{ll}\text { - } & \text { Varietas padi yang } \\
\text { digunakan }\end{array}$} & Sesuai rekomendasi & 12 & 40 \\
\hline & $\begin{array}{l}\text { Varietas unggul tapi tidak sesuai } \\
\text { rekomendasi }\end{array}$ & 18 & 60 \\
\hline & Bukan varietas unggul & - & 0 \\
\hline \multirow{3}{*}{$\begin{array}{ll} & \text { Pelaksanan tahapan } \\
\text { persemaian } & \end{array}$} & Seluruh tahapan dilakasanakan & 12 & 40 \\
\hline & Sebagian tahapan dilaksanakan & 18 & 60 \\
\hline & $\begin{array}{l}\text { Tidak melakukan tahapan } \\
\text { persemaian }\end{array}$ & - & 0 \\
\hline \multirow{3}{*}{$\begin{array}{l}\text { - Jumlah } \\
\text { lubang }\end{array}$} & 1 bibit perlubang & - & 0 \\
\hline & 2-4 bibit perlubang & 30 & 100 \\
\hline & 5-6 bibit perlubang & - & 0 \\
\hline \multirow[t]{3}{*}{$\begin{array}{ll}- & \text { Pengaturan } \\
\text { tanam }\end{array}$} & $\begin{array}{l}\text { Menggunakan sistem pengaturan } \\
\text { jarak tanam }\end{array}$ & 3 & 10 \\
\hline & $20 \times 20 \mathrm{~cm}$ & 27 & 90 \\
\hline & Tidak ada pengaturan jarak tanam & - & 0 \\
\hline \multirow[t]{3}{*}{ - $\quad$ Pengairan berselang } & Sesuai anjuran & 14 & 46,67 \\
\hline & Kurang sesuai anjuran & 16 & 53,33 \\
\hline & $\begin{array}{lll}\text { Tidak melakukan } & \text { pengairan } \\
\text { berselang }\end{array}$ & - & 0 \\
\hline \multirow[t]{3}{*}{ - Pemupukan } & Sesuai rekomendasi & 6 & 20 \\
\hline & $\begin{array}{l}\text { Dilakukan pemupukan tapi tidak } \\
\text { sesuai rekomendasi }\end{array}$ & 24 & 80 \\
\hline & Tidak melakukan pemupukan & - & 0 \\
\hline \multirow{3}{*}{$\begin{array}{l}\text { - Teknik pengendalian } \\
\text { hama terpadu }\end{array}$} & Melakukan secara terpadu & 15 & 50 \\
\hline & $\begin{array}{l}\text { Mengendalikan hama dengan teknik } \\
\text { tertentu }\end{array}$ & 15 & 50 \\
\hline & Tidak mengendalikan hama & - & 0 \\
\hline \multicolumn{4}{|l|}{ Pemanfaatan musuh alami } \\
\hline \multirow{3}{*}{$\begin{array}{ll}\text { - } & \text { Mengenali } \\
\text { musuh alami }\end{array}$} & $>5$ jenis musuh alami & 14 & 46,67 \\
\hline & $2-5$ jenis musuh alami & 16 & 53,33 \\
\hline & 1 atau tidak tahu jenis musuh alami & - & 0 \\
\hline \multirow{3}{*}{$\begin{array}{l}\text { - Pemanfaatan } \\
\text { alami }\end{array}$} & Memanfaatkan & - & 0 \\
\hline & Kurang Memanfaatkan & 25 & 83,33 \\
\hline & Tidak memanfaatkan & 5 & 16,67 \\
\hline \multicolumn{4}{|l|}{ Pengamatan rutin } \\
\hline \multirow[t]{3}{*}{ - Rutinitas pengamatan } & Seminggu sekali & 3 & 10 \\
\hline & Rutin tapi tidak setiap minggu & 27 & 90 \\
\hline & Tidak melakukan pengamatan rutun & - & 0 \\
\hline \multirow{2}{*}{$\begin{array}{ll} & \begin{array}{l}\text { Ruang } \\
\text { pengamatan }\end{array}\end{array}$} & Seluruh kegiatan dilaksanakan & - & 0 \\
\hline & Hanya sebagian dilaksanakan & 30 & 100 \\
\hline
\end{tabular}




\begin{tabular}{|c|c|c|c|c|}
\hline & & Tidak melakukan pengamatan rutin & - & 0 \\
\hline \multirow[t]{3}{*}{$\begin{array}{l}\text { Penggunaan } \\
\text { secara bijak }\end{array}$} & \multirow[t]{3}{*}{ pestisida } & $\begin{array}{l}\text { Penggunaan pestisida sebagai } \\
\text { alternatif terakhir }\end{array}$ & - & 0 \\
\hline & & $\begin{array}{l}\text { Kombinasi pestisida dengan teknik } \\
\text { lain }\end{array}$ & 30 & 100 \\
\hline & & Pestisida sebagai alternatif pertama & - & 0 \\
\hline
\end{tabular}

Tabel 4 menunjukkan bahwa petani Kelurahan Liabuku hanya sebagian yang menggunakan varietas padi sesuai rekomendasi penyuluh pertanian, yaitu sebesar 40\%, sisanya $60 \%$ menggunakan varietas unggul tapi tidak sesuai rekomendasi. Untuk pelaksanaan tahapan persemaian, hanya $40 \%$ petani melaksanakan semua tahapan persemaian, $60 \%$ hanya melaksanakan sebagian tahapan persemaian. Sebagian besar responden jarang melakukan seleksi benih karena mereka menganggap penyeleksian benih dengan memasukan benih kedalam larutan abu dapur dan memisahkan antara benih yang terapung dan tenggelam akan memakan waktu dan tenaga sehingga mereka lebih mengambil praktisnya saja dengan langsung memgecambahkan benih dengan melakukan pemeraman antara 1-2 malam. Sebelum menyebarkan benih, petani menyiapkan lahan persemaian terlebih dahulu yaitu dengan memperhatikan kesuburan tanah, cahaya matahari dan pengairannya.

Penggunaan jumlah bibit per lubang, semua petani responden memasukkan 2 hingga 4 bibit pada satu lubang tanam. Bukan 1 bibit 1 lubang seperti yang disarankan penyuluh, karena petani beranggapan semakin banyak bibit yang ditanam semakin banyak pula padi yang akan mereka panen. Pada pengaturan jarak tanam, terdapat $90 \%$ petani mengatur jarak tanam pada ukuran $20 \times 20 \mathrm{~cm}$, sisanya (10\%) menggunakan metode pengaturan jarak tanam, seperti jajar legowo, karena beranggapan bahwa penggunaan sistem itu tergolong rumit. Pada pengairan berselang, sebanyak $46,67 \%$ petani melaksanakan pengairan berselang sesuai anjuran, sisanya $(53,33 \%)$ melakukan pengairan tapi tidak sesuai anjuran, hal ini disebabkan keterbatasan jumlah air untuk pengairan. Untuk pemupukan, sebanyak $80 \%$ petani melakukan pemupukan tapi tidak sesuai rekomendasi, hanya $20 \%$ yang melakukan pemupukan sesuai rekomendasi. Hal ini terjadi karena petani mengalami kesulitan untuk mendapatkan pupuk dan keterbatasan modal untuk membeli pupuk. Sedangkan untuk teknik pengendalian hama terpadu, sebagian petani $(50 \%)$ melakukan pengendalian hama secara terpadu, dan sisanya $50 \%$ melaksanakan pengendalian hama dengan teknik tertentu.

Tingkat adopsi komponen PHT untuk pemanfaatan musuh alami pada Tabel 4 menunjukkan bahwa sebanyak 46,67\% petani mengenali musuh alami hama lebih dari 5 jenis, sisanya 53,33\% hanya mengenali 2 hingga 5 jenis musuh alami hama yang berguna untuk mengendalikan populasi hama secara alami di tanaman padi sawah petani. Sebanyak 83,33\% petani kurang memanfaatkan adanya musuh alami, sisanya $(16,67 \%)$ tidak memanfaatkan musuh alami.

Pengamatan rutin adalah teknik penerapan pengendalian hama dengan melakukan pengamatan secara rutin pada tanaman padi. Sebanyak $90 \%$ petani melakukan pengamatan rutin tapi tidak setiap minggu, dan sisanya $10 \%$ petani yang melakukan pengamatan seminggu sekali. Untuk ruang lingkup pengamatannya, semua petani hanya melakukan sebagian tahapan pengamatan, tidak keseluruhan. Alasan mereka adalah beberapa tahapan pengamatan merepotkan pekerjaan mereka, seperti mengamati ada tidaknya musuh alami hama tanaman padi sawah. Tabel 4 juga menunjukan bahwa penggunaan pestisida secara bijak adalah semua petani tidak menjadikan pestisida sebagai alternatif terakhir tetapi mengkombinasikan pestisida dengan teknik lain, alasannya mereka ingin cepat melihat hasil penyemprotan/pemberantasan hama tersebut, jika mengandalkan pemanfaatan musuh alami, 
sangat lambat terlihat hasilnya karena proses kerja musuh alami dalam mematikan hama dilakukan secara berangsur-angsur tidak langsung mematikan hama. Untuk melihat hubungan karakteristik inovasi dengan tingkat adobsi komponen PHT dilakukan analisis korelasi pada data kuesioner responden dan hasilnya dapat dilihat pada Tabel 5.

Tabel 5. Nilai korelasi hubungan karakteristik inovasi dengan tingkat adobsi komponen PHT

\begin{tabular}{|c|c|c|c|c|c|}
\hline & & $\begin{array}{l}\text { Budidaya } \\
\text { Tanaman } \\
\text { Sehat } \\
\end{array}$ & $\begin{array}{l}\text { Pemanfaatan } \\
\text { Musuh } \\
\text { Alami } \\
\end{array}$ & $\begin{array}{l}\text { Pengamatan } \\
\text { Rutin }\end{array}$ & $\begin{array}{l}\text { Penggunaan } \\
\text { Pestisida Secara } \\
\text { Bijak }\end{array}$ \\
\hline \multirow[t]{2}{*}{ Keuntungan } & $\begin{array}{l}\text { Korelasi } \\
\text { Pearson }\end{array}$ & - & - & - & - \\
\hline & Nilai Sig. & - & - & - & - \\
\hline \multirow[t]{2}{*}{ Kompatibilitas } & $\begin{array}{l}\text { Korelasi } \\
\text { Pearson }\end{array}$ & 0,045 & $-0,361^{*}$ & $-0,181$ & - \\
\hline & Nilai Sig. & 0,813 & 0,050 & 0,337 & - \\
\hline \multirow[t]{2}{*}{ Kompleksitas } & $\begin{array}{l}\text { Korelasi } \\
\text { Pearson }\end{array}$ & 0,247 & 0,070 & $-0,447^{*}$ & - \\
\hline & Nilai Sig. & 0,189 & 0,714 & 0,013 & - \\
\hline \multirow[t]{2}{*}{ Triabilitas } & $\begin{array}{l}\text { Korelasi } \\
\text { Pearson }\end{array}$ & - & - & - & - \\
\hline & Nilai Sig. & - & - & - & - \\
\hline \multirow[t]{2}{*}{ Observabilitas } & $\begin{array}{l}\text { Korelasi } \\
\text { Pearson }\end{array}$ & - & - & - & - \\
\hline & Nilai Sig. & - & - & - & - \\
\hline
\end{tabular}

Tabel 5 memperlihatkan terdapat beberapa nilai korelasi yang dapat ditampilkan, yaitu untuk hubungan kompatibilitas dengan budidaya tanaman sehat, kompatibilitas dengan pemanfaatan musuh alami, kompatibilitas dengan pengamatan rutin, kompleksitas dengan budidaya tanaman sehat, kompleksitas dengan pemanfaatan musuh alami dan kompleksitas dengan pengamatan rutin. Kelompok data yang lain tidak ada karena tidak ada variasi data (nilai standar deviasi keuntungan, triabilitas, observabilitas dan penggunaan pestisida secara bijak sebesar 0). Jika standar deviasi suatu kelompok data bernilai 0 maka pasti akan terjadinya error akibat pembagian 0 pada perhitungan nilai korelasi Pearson.

Berdasarkan nilai sig pada Tabel 5 terlihat hanya terjadi hubungan nyata antara karakteristik inovasi kompatibilitas dengan pemanfaatan musuh alami (nilai sig lebih kecil atau sama dengan 0,05 , dalam hal ini sebesar 0,05 ) dan kompleksitas dengan pengamatan rutin (nilai sig lebih kecil 0,05, yaitu sebesar 0,013). Arti adanya hubungan kompatibilitas dengan pemanfaatan musuh alami adalah karakteristik teknologi inovasi pengendalian hama terpadu yang sesuai dengan kebutuhan pengendalian hama padi sawah memiliki hubungan nyata dengan tingkat adopsi komponen PHT yaitu pemanfaatan musuh alami. Petani hanya mengenal 2-5 jenis musuh alami dan kurang memanfaatkan musuh alami tersebut sebagai langkah awal pengendalian hama, mereka lebih memilih cara mengkombinasikan pestisida dengan teknik pengendalian hama lainnya, karena cara ini menurut petani lebih sesuai untuk pengendalian hama padi sawah yaitu mudah diamati proses dan hasilnya.

Karakteristik teknologi inovasi pengendalian hama terpadu lain yang memiliki hubungan nyata adalah kompleksitas dengan pengamatan rutin yang memiliki nilai sig 0,013 , lebih kecil dari 0,05 , yaitu kemudahan teknologi inovasi pengendalian hama terpadu untuk 
dimengerti dan mudah dilaksanakan memiliki hubungan nyata dengan pengamatan rutin, yaitu petani melakukan pengamatan rutin tetapi tidak setiap minggu. Pengamatan rutin yang dilakukan petani walaupun tidak setiap minggu memberikan kemudahan bagi petani untuk menerapkan teknologi inovasi pengendalian hama terpadu.

\section{KESIMPULAN DAN SARAN}

berikut:

Berdasarkan hasil penelitian dan pembahasan, maka dapat disimpulkan sebagai

1. Karakteristik inovasi petani padi sawah di Kelurahan Liabuku adalah semua petani menyatakan bahwa inovasi memberikan keuntungan relatif bagi petani, $60 \%$ petani menyatakan ada kesesuaian inovasi dengan kebutuhan pengendalian hama padi sawah, dan $40 \%$ responden menyatakan inovasi kadang tidak sesuai dengan kebutuhan. Untuk kompleksitas sebesar 83,33\% petani menyatakan inovasi tersebut mudah dimengerti dan dilaksanakan, dan $16,67 \%$ petani yang menyatakan inovasi tersebut sedang (cukup) untuk dimengerti dan dilaksanakan. Untuk triabilitas, semua petani menyatakan bahwa inovasi tersebut mudah dicoba terlebih dahulu dalam ukuran/skala kecil, dan untuk observabilitas, semua petani menyatakan bahwa inovasi tersebut mudah diamati proses dan hasilnya.

2. Tingkat adopsi petani SLPHT terhadap komponen PHT tanaman padi sawah di Kelurahan Liabuku adalah $40 \%$ petani menggunakan varietas padi sawah sesuai rekomendasi, 60\% menggunakan padi unggul tidak sesuai rekomendasi. Untuk persemaian sebesar $40 \%$ melaksanakan semua tahapan persemaian, dan $60 \%$ hanya melaksanakan sebagian tahapan persemaian. Semua petani memasukan 2 hingga 4 bibit per lubang pada saat persemaian. Pada pengaturan jarak tanam terdapat $90 \%$ petani mengatur jarak tanam pada ukuran $20 \times 20 \mathrm{~cm}$, sisanya menggunakan $10 \%$ metode lain. Untuk pengairan berselang sebanyak $46,67 \%$ petani melaksanakan pengairan berselang sesuai anjuran dan 53,33\% melakukan pengairan berselang tapi tidak sesuai anjuran. Untuk pemupukan, $20 \%$ petani melakukan pemupukan sesuai rekomendasi, dan $80 \%$ petani melaukan pemupukan tidak sesuai rekomendasi. Untuk pengendalian hama terpadu, 50\% petani melakukan PHT, sisanya, yaitu 50\% melakukan pengendalian hama dengan teknik tertentu. Untuk pemanfaatan musuh alami, 83,33\% petani kurang memanfaatkan musuh alami, sisanya, $16,67 \%$ tidak memanfaatkan musuh alami. Untuk pengamatan rutin, $90 \%$ petani melakukan pengamatan rutin tapi tidak tiap minggu, hanya $10 \%$ petani yang melakukan tiap minggu. Dan pengamatan yang dilakukan hanya sebagian tahapan pengamatan. Untuk penggunaan pestisida secara bijak, semua petani mengkombinasikan pestisida dengan teknik lain.

3. Ada hubungan yang signifikan antara karakteristik inovasi kompatibilitas dengan pemanfaatan musuh alami yang ditunjukan dengan nilai sig korelasi adalah 0,05 lebih kecil atau sama dengan 0,05. Terdapat hubungan yang signifikan antara kompleksitas dengan pengamatan rutin yang ditunjukan dengan nilai sig korelasi adalah 0,013 lebih kecil 0,05 .

Saran yang dapat disampaikan melalui penelitian ini adalah sebagai berikut:

1. Diharapkan petani yang sudah mengikuti SLPHT lebih aktif untuk mentransfer penggetahuan yang diperolehnya selama mengikuti SLPHT kepada petani non SLPHT.

2. Diharapkan pemerintah agar menyediakan komponen pengendalian agens hayati untuk pengendalian hama dan penyakit. 
3. Diperlukan penelitian lebih lanjut untuk meneliti mengenai produktivitas dari penerapan komponen PHT pada tanaman padi.

\section{DAFTAR PUSTAKA}

Departemen Pertanian. 1997. Panduan Pelaksanaan sekolah Lapang Pengendalian Hama terpadu (SLPHT). Departemen Pertanian. Jakarta.

Dinas Pertanian Kota Baubau 2017

Direktorat Perlindungan tanaman. 2002. Teknologi Pengendalian Hama Terpadu. Direktorat Perlindungan Tanaman. Jakarta.

Mardikanto, T dan Sutarni. 1982. Pengantar Penyuluhan Pertanian dalam Teori dan Praktek. Hapsara. Surakarta

Mardikanto, T. 1993. Penyuluhan Pembangunan Pertanian. UNS Press. Surakarta.

Maslow, A.H. 1984. Motivasi dan Kepribadian (terjemahan). Jakarta: PT. Pustaka Binaman Pressindo

Mosher, A.T. 1987. Menggerakkan dan Membangun Pertanian. Jakarta: CV. Yasaguna.

Oka, I. N dan Bahagiawati, A. H. 1995. Pengendalian Hama Terpadu. Balai Penelitian Tanaman Pangan. Bogor.

Pracaya. 2004. Hama dan Penyakit Tanaman. Penebar Swadaya. Depok

Rogers, M. Everett. 1971. Diffusion of Innovation. Collier Macmillan Publisher. London. 